\title{
Current Status of Organ Preservation in Carcinoma Larynx
}

\author{
Tapesh Bhattacharyya ${ }^{a}$, Cessal Thommachan Kainickal ${ }^{\mathrm{b}, \mathrm{c}}$
}

\begin{abstract}
Organ preservation in carcinoma larynx is a long debated topic. There are multiple organ preserving approaches in the management of carcinoma larynx depending on various factors. Radical radiotherapy (RT) and conservation laryngeal surgery have shown equivalent results in early laryngeal cancer. Concurrent chemoradiation (CTRT) is the standard treatment in stage III and IV laryngeal cancer with intact cartilage and functional larynx. Patients with cartilage destruction or dysfunctional larynx are not the candidates for organ preservation. This systematic review is aimed at discussing the evolution of different organ preserving approaches, their efficacy, impact on voice quality, their pitfalls and future directions.
\end{abstract}

Keywords: Organ preservation; Larynx

\section{Introduction}

Laryngeal cancer consists of $1.1 \%$ of all new cancers worldwide. It is the seventh most common cause of cancer in males in India [1]. The incidence of laryngeal cancer has been reported to be $1.26-8.18$ per 100,000 population in different regions in the country [2]. Early stage laryngeal cancers include T1 and most T2 squamous cell cancers of glottis and supraglottic regions. Subglottic cancers are relatively rare. Multiple treatment options exist for early stage squamous cell carcinoma of the larynx. Multidisciplinary approach is highly encouraged for the management.

\section{Organ Preserving Approach in Early Glottis Cancer (T1, T2NOM0)}

Treatment options include radical radiotherapy (RT), transoral laser surgery (TLS), and function preserving open partial laryngectomy [3]. Treatment selection depends on various fac-

Manuscript submitted April 10, 2018, accepted April 20, 2018

aDivison of Radiation Oncology, Tata Medical Center, Kolkata, India

bivision of Radiation Oncology, Regional Cancer Centre, Trivandrum, India ${ }^{\mathrm{c} C}$ Corresponding Author: Cessal Thommachan Kainickal, Division of Radiation Oncology, Regional Cancer Centre, Trivandrum, India.

Email: drcessalthomas@gmail.com

doi: https://doi.org/10.14740/wjon1105w tors including disease extent into supraglottis and subglottis, anterior commissure involvement, patient's preference, occupational considerations, voice quality, performance status, patient's compliance, comorbidities, physician's expertise, treatment cost and physician's bias. All the treatments are associated with excellent tumor control. Mendenhall et al discussed this particular issue in three angles: local control, voice quality and cost [3]. In University of Florida, patients with limited well-defined T1a N0M0 glottic cancers are treated with either RT or TLS. The remaining all patients with T1N0 and T2N0 lesions are treated with definitive RT. They concluded that the rates of local control, voice preservation and survival are comparable for patients treated with RT, TLS and open partial laryngectomy. Open partial laryngectomy is preferred in those who experience local disease recurrence.

\section{Radical RT Versus Conservation Laryngeal Surgery in Early Glottic Cancer}

The goal of treatment in early glottic cancer is to achieve cure with best functional outcome. At present, radical RT and TLS are standard upfront treatments for early glottic cancer [4]. As both the modalities offer excellent and equivalent cure rates, there is long standing debate on the merit of each modality in the treatment of early glottic cancer with regard to its efficacy and functional outcome.

In a study by Aaltonen et al [5], male patients with carcinoma limited to one mobile cord were randomized to receive either laser surgery or external beam radiotherapy (EBRT). EBRT dose was 66 Gy with 2 Gy/\# over 6.5 weeks. Overall the voice qualities between the groups were rated similar but patients treated with RT reported less hoarseness-related inconvenience in daily living 2 years after treatment. They concluded that RT may be the treatment of choice for patients whose requirements for voice quality are demanding. Dinapoli et al [6] compared the oncological outcome and voice quality among a uniform and well-defined subset of patients with T1 glottic carcinoma. No statistically significant differences were found between the two groups in terms of overall survival and disease-free survival; even sub-classifying patients into stages T1a and T1b also made no difference. The median voice handicap index (VHI) score for patients undergoing RT was 4, while for surgical patients, it was 18 ( $\mathrm{P}<0.0001)$. Remmelts et al [7] showed comparable oncological outcome between the TLS and RT arm.VHI scores were $12.4 \pm 8.9$ for laser surgery and $8.3 \pm 7.7$ for RT $(\mathrm{P}<0.05)$, with a higher score reflecting a worse outcome. VHI scores per tumor stage for laser surgery and RT were $12.0 \pm 9.9$ and $7.9 \pm 7.5$ in T1a 
Table 1. Radiotherapy Versus TLS in Stage I Glottic Cancer

\begin{tabular}{|c|c|c|c|c|c|}
\hline Author & Year & No. of patients & Local control & Larynx preservation & Voice quality \\
\hline $\begin{array}{l}\text { Aaltonen } \\
\text { et al [5] }\end{array}$ & 2014 & RT 28; TLS 32 & $\begin{array}{l}\text { At } 2 \text { years, } 88 \% \text { in } \\
\text { RT vs. } 90 \% \text { TLS }\end{array}$ & Not available & $\begin{array}{l}\text { Overall voice quality similar in both arms. Voice } \\
\text { more breathy in TLS; less hoarseness-related } \\
\text { inconvenience in RT. }\end{array}$ \\
\hline $\begin{array}{l}\text { Remmelts } \\
\text { et al [7] }\end{array}$ & 2013 & RT 159; TLS 89 & $\begin{array}{l}\text { At } 5 \text { years, } 86 \% \\
\text { in RT vs. } 75 \% \text { in } \\
\text { TLS }(P=0.07)\end{array}$ & $\begin{array}{l}5 \text {-year } 83 \% \text { in RT vs. } \\
93 \% \text { in TLS }(P<0.05)\end{array}$ & $\begin{array}{l}\text { VHI } 12.4 \pm 8.9 \text { in TLS vs. } 8.3 \pm 7.7 \text { in } \mathrm{RT}(\mathrm{P}<0.05) \\
\text { suggestive of poor outcome of TLS }\end{array}$ \\
\hline $\begin{array}{l}\text { van Gogh } \\
\text { et al [9] }\end{array}$ & 2012 & RT 39: TLS 67 & $\begin{array}{l}\text { At } 2 \text { years, } 95 \% \text { in } \\
\text { RT vs. } 97 \% \text { in TLS }\end{array}$ & $\begin{array}{l}\text { At } 2 \text { years, } 95 \% \text { in } \\
\text { RT vs. } 100 \% \text { in TLS }\end{array}$ & $\begin{array}{l}\text { Shimmer score mean } 5.06 \text { in TLS vs. } 5.39 \text { in RT; } \\
\text { voice outcome recovery earlier in TLS. }\end{array}$ \\
\hline $\begin{array}{l}\text { Dinapoli } \\
\text { et al [6] }\end{array}$ & 2010 & RT 70; TLS 73 & $\begin{array}{l}\text { Equal oncological } \\
\text { outcome }\end{array}$ & & Median VHI 18 in TLS vs. 4 in RT $(\mathrm{P}<0.0001)$ \\
\hline
\end{tabular}

$(\mathrm{P}=0.06), 16.7 \pm 9.0$ and $4.9 \pm 6.6$ in $\mathrm{T} 1 \mathrm{~b}(\mathrm{P}<0.05)$, respectively. Depth of laser resection has impact on voice deficiency and patients with T1b lesion had higher voice deficiency if treated with laser surgery. Abdurehim et al [4] in their metaanalysis showed that no significant differences were observed between TLS and RT with respect to local control, survival and voice quality. Results of latest studies on RT vs. TLS are shown in Table 1 [5-9].

RT is a time tested approach. RT planning for early glottic cancer is simple and it does not require sophisticated technology. RT has proven to be of high efficacy with better or equivalent voice outcome. TLS is quicker and repeatable and has many salvage options. Moreover, this kind of studies has some limitations because of their small sample size, retrospective nature and selection bias. It is still unclear which of these modalities is to be considered optimum and the differences in outcome between the groups are too subtle.

The vertical partial laryngectomy comprises of vertical transection of thyroid cartilage and glottic resection extending into the paraglottic space. The goal of this surgery is resection of a portion of thyroid cartilage with the cancer at glottic level, while preserving the posterior paraglottic space. Hence, it is most suitable for early glottic cancer without anterior commissure involvement [10]. In 1994, Thomas et al [11] reported a series of 159 patients with T1 glottic cancer who underwent vertical partial laryngectomy at the Mayo Clinic between 1976 and 1986. The 5-year local control rate was 93\% and in 94\% of the patients, the larynx could be preserved. Spector et al [12] treated 404 patients with T1 glottic cancer with a 5-year local control rate of $92 \%$ and larynx preservation rate of $93 \%$. In 71 patients with T2 glottic carcinoma, the 5-year disease-specific survival rate was $92 \%$. The larynx preservation rate was $92 \%$. The updated Cochrane review [13] identified only one randomized controlled trial, which compared open surgery and RT in 234 patients with early glottic laryngeal cancer. For T1 tumors, the 5-year survival was $91.7 \%$ following RT and $100 \%$ following surgery and for T2 tumors, $88.8 \%$ following RT and $97.4 \%$ following surgery. There were no significant differences in survival between the two groups. For T1 tumors, the 5-year disease-free survival rate was $71.1 \%$ following RT and $100.0 \%$ following surgery, and for the T2 tumors, $60.1 \%$ following RT and $78.7 \%$ following surgery. Only the latter comparison was statistically significant $(\mathrm{P}=0.036)$, but statistical significance would not have been achieved with a two-sided test. Data on voice quality and quality of life are not available. To conclude RT and conservation laryngeal surgery provides equivalent local control and functional outcome. Narrow margin followed by postoperative RT is not considered as an acceptable treatment approach.

\section{Organ Preserving Surgeries for Early Supraglot- tic Cancers (T1, T2NOM0)}

The primary difference between supraglottic cancers and true glottis cancers is the likelihood of developing cervical lymph node metastasis. The rate of cervical lymph node metastasis from supraglottic larynx ranges from $10 \%$ to $50 \%$ with an average of $33 \%$. Hence neck treatment is mandatory [14]. Surgical treatment options for supraglottic carcinomas comprise open supraglottic laryngectomy, transoral laser microsurgery, and supracricoid partial laryngectomy with cricohyoidopexy (SCPL-CHEP). The open supraglottic laryngectomy consists of a resection of the entire supraglottis such as the epiglottis, the preepiglottic fat, and the ventricular folds together with the supraglottic part of the thyroid cartilage. The oncologic results of open supraglottic laryngectomy in early supraglottic carcinomas are excellent. The local control rate is between $90 \%$ and $100 \%$ for T1 tumors and $80 \%$ and $97 \%$ for T2 tumors [10]. Prades et al [15] report on 110 patients with T1-T3 supraglottic carcinomas. The local control rate was $90.3 \%$ and the 5-year overall survival rate was $52 \%$.

The indication for this SCPL-CHEP comprises supraglottic tumors with limited infiltration of the preepiglottic fat, limited erosion of the thyroid cartilage and tumors with fixation of one vocal cord but without fixation of the arytenoid cartilage. This operation was used for surgical treatment of T1, T2 and selected T3 and T4 supraglottic tumors. Schwaab et al [16] report on 146 patients mostly with $\mathrm{T} 2$ and $\mathrm{T} 3$ carcinomas who underwent SCPL-CHP. The local control rate was very good, with only $4 \%$ developing local recurrence. The larynx could be 
preserved in $85 \%$ of patients. The 5 -year overall survival rate was $88 \%$. The local recurrence reported in other studies is also very low ranging from $0 \%$ to $7 \%[17,18]$.

Always those patients who are taken up for organ preservation should be treated with a single modality treatment. Every effort should be made to avoid combining surgery with radiation therapy because functional outcomes may be compromised by combined modality therapy; single modality treatment is effective for limited stage disease. Treatment options include radical RT or organ preserving surgery.

\section{Organ Preserving Approaches in Locally Ad- vanced Laryngeal Cancer (Stage III and IV)}

Approximately 25 years ago, the standard treatment of locally advanced laryngeal cancer was total laryngectomy plus conventional postoperative RT. There was a paradigm shift with the emergence of induction chemotherapy as a part of larynx preserving treatment in 1991 when veteran affairs (VA) trial was published [19]. The landmark VA trial [19] enrolled 332 patients which were randomized to receive three cycles of chemotherapy (cisplatin $+5 \mathrm{FU}$ ) and RT versus surgery and RT. The clinical tumor response was assessed after two cycles of chemotherapy and patients with partial response received third cycle of chemotherapy followed by definitive RT of 66 70 Gy. Patients who were not able to achieve partial response underwent surgery followed by postoperative RT. The combined rates of partial and complete response in the primary tumor and the regional nodes after two or three cycles of chemotherapy were $85 \%$ and $98 \%$, respectively. After a median follow-up of 33 months, the estimated 2-year survival was $68 \%$ for both the arms. More local relapse and fewer distant relapse were seen in the chemotherapy group as compared to surgery group. The larynx was successfully preserved in 64\% without jeopardizing the 2-year survival as compared to upfront surgery group. One-fourth of the patients had T4 disease and patients with cartilage erosion were also included in this study. Salvage laryngectomy was required in $44 \%$ patients with stage IV as compared with $29 \%$ of patients with stage III disease (P $=0.048$ ). A total of $56 \%$ patients with T4 disease underwent salvage laryngectomy compared to $29 \%$ with smaller primary tumors $(\mathrm{P}=0.001)$. Hence, patients with cartilage destruction are not the candidates for organ preservation approach. This landmark trial established induction chemotherapy followed by RT as an alternative to laryngectomy for locally advanced laryngeal cancer. To determine the contribution of chemotherapy and RT to larynx preservation and the optimum sequence of chemotherapy and RT, the RTOG and Head and Neck Intergroup conducted a randomized trial [20] to investigate three radiation-based schedules.

Induction cisplatin plus 5FU followed by RT (good responders to chemotherapy) experimental group in VA trial, chemoradiation (CTRT) and RT alone. The rationale for the second group was based on enhancement of radiation effect on tumor cells with concurrent administration of injection cisplatin. The primary objective was to compare trials of laryngeal preservation in three arms. Patients with large volume T4 disease (defined as penetration through cartilage) or extending more than $1 \mathrm{~cm}$ base of tongue were excluded from this study. Most of the patients $(72 \%)$ were of carcinoma supraglottis. Most of the patients presented with T3 with fixed cord involvement (44\%). At a median follow-up of 3.8 years, patients receiving CTRT had a significantly higher rate of larynx preservation rate $(84 \%)$ vs. induction chemotherapy followed by RT $(72 \% ; \mathrm{P}=0.005)$ or RT alone $(67 \% ; \mathrm{P} \leq 0.001)$. There was no difference between induction chemotherapy group versus RT alone group in terms of laryngeal preservation. There was no difference among the three treatment groups with regard to speech at either 12 or 24 months of follow-up.

In the long term update of the landmark RTOG 91-11 study [21], 520 patients were analyzed. Median follow-up period was 10.8 years. Both the chemotherapy regimens significantly improved laryngectomy free survival compared with RT alone (induction chemotherapy versus RT alone; hazard ratio (HR), 0.75; 95\% CI, 0.59 - 0.95; $\mathrm{P}=0.02$; concurrent CTRT versus RT alone: HR, 0.78; 95\% CI, $0.78-0.98$; $\mathrm{P}=0.03$ ). Overall survival did not differ significantly in any of the treatment arm, with 5- and 10-year estimates of 58\% and 39\% for induction, $55 \%$ and $28 \%$ for CTRT and $54 \%$ and $32 \%$ for RT alone, respectively. After about 4.5 years, the curves begin to separate favoring induction, although the difference is not statistically significant. However, deaths in the CTRT arm was laryngeal cancer unrelated deaths. This occurred without increase in late toxicities.

\section{Outcome of Salvage Total Laryngectomy Fol- lowing Organ Preservation Therapy}

Weber et al [22] evaluated the incidence of morbidity, mortality and disease control for patients requiring salvage total laryngectomy following organ preservation in RTOG 91-11 trial. From 1992 - 2000, 517 evaluable patients were randomized to receive chemotherapy followed by RT (arm 1), CTRT (arm 2) or RT (arm 3). Overall total laryngectomy was required in 129 patients. The salvage laryngectomy rates were $28 \%, 16 \%$ and $31 \%$ in arms 1,2 and 3 , respectively $(\mathrm{P}=0.002)$. Following total laryngectomy, the incidence of major and minor complications ranged from $52 \%$ to $59 \%$ and did not differ significantly among the three arms. Locoregional control following salvage total laryngectomy was 74\% for arms 1 and 2 and 90\% for arm 3. At 24 months, the overall survival was 69\% (arm 1), 71\% (arm 2) and 76\% (arm 3) (P>0.73). Laryngectomy following organ preservation treatment was associated with acceptable morbidity. Survival following salvage laryngectomy was not influenced by the initial organ preservation treatment.

\section{Induction Chemotherapy in Laryngeal Preserva- tion}

The Groupe Oncologie Radiotherapie Tete et Cou (GORTEC) trial [23] showed the effect of adding docetaxel to the PF (cisplatin, 5FU) induction chemotherapy regime on larynx preservation. Patients with laryngeal or hypopharyngeal cancers 
Table 2. Results of Organ Preserving Approaches in Advanced Laryngeal Cancer

\begin{tabular}{|c|c|c|c|c|}
\hline Study & Year & Arms & Outcome & Laryngeal preservation \\
\hline VA trial [19] & 1991 & $\begin{array}{l}\text { Induction chemo } \\
\text { followed by RT } \\
\text { vs. surgery + RT }\end{array}$ & $\begin{array}{l}\text { After two cycles of chemo clinical CR } 31 \% \text {, PR } \\
54 \%, 2 \text {-year survival } 68 \% \text { in both the groups. } \\
36 \% \text { of the patients of chemotherapy group } \\
\text { required total laryngectomy. }\end{array}$ & $\begin{array}{l}\text { Overall larynx preservation was } 64 \% \text { in the } \\
\text { nonsurgical arm. }\end{array}$ \\
\hline $\begin{array}{l}\text { GORTEC } \\
\text { trial }[23]\end{array}$ & $\begin{array}{l}2000- \\
2001\end{array}$ & $\begin{array}{l}\text { Induction chemo } \\
\text { with TPF vs. } \\
\text { PF followed by } \\
\text { radiotherapy or } \\
\text { surgery according } \\
\text { to the response }\end{array}$ & $\begin{array}{l}\text { Overall response rate after induction } \\
\text { chemotherapy was higher with TPF }(80 \% \text { versus } \\
59 \%(\mathrm{P}=0.002) \text {. There was no significant } \\
\text { difference between the treatment arms in the } \\
3 \text {-year rate of overall }(60 \% \text { in each arm) or } \\
\text { disease-free }(58 \% \text { with TPF versus } 44 \% \text { with } \\
\text { PF) survival }\end{array}$ & $\begin{array}{l}\text { The } 3 \text {-year larynx preservation rate was } \\
\text { significantly higher in the TPF arm than in the } \\
\text { PF arm }(70 \% \text { versus } 58 \% ; \mathrm{P}=0.03) \text {. }\end{array}$ \\
\hline $\begin{array}{l}\text { RTOG } \\
91-11[20]\end{array}$ & 2003 & $\begin{array}{l}\text { RT vs. induction } \\
\text { chemo followed } \\
\text { by RT vs. CTRT }\end{array}$ & $\begin{array}{l}\text { At a median follow-up of } 3.8 \text { years local control } \\
\text { significantly better in CTRT arm }(78 \%) \text { vs. } \\
\text { induction chemo followed by RT }(61 \%) \text { vs. RT } \\
\text { alone }(56 \%) \text {. Overall survival similar in all three } \\
\text { groups }\end{array}$ & $\begin{array}{l}\text { Larynx preservation was significantly higher } \\
\text { in the CTRT arm }(88 \%) \text { as compared to } \\
\text { induction chemo followed by RT }(75 \% ; \mathrm{P}= \\
0.005) \text { ) or RT alone }(70 \% ; \mathrm{P} \leq 0.001) \text {. }\end{array}$ \\
\hline
\end{tabular}

requiring total laryngectomy were randomized to receive induction therapy with three 21-day cycles of either PF or TPF (docetaxel, cisplatin, 5FU). Patients responding to induction chemotherapy received conventionally fractionated RT (total dose of 70 Gy). Non-responders underwent total laryngectomy followed by RT. In this trial, a total of 213 patients were randomized. After induction chemotherapy, 20\% of patients in the TPF arm and $16 \%$ patients in the PF arm received CTRT. At a median follow-up of 36 months, the 3-year larynx preservation rate was significantly higher in the TPF arm $(70 \%)$ as compared to $\mathrm{PF}$ arm $(58 \%)(\mathrm{P}=0.03)$. The overall response rate after induction chemotherapy was also higher in the TPF arm as compared to PF arm (80\% vs. $59 \%$; P = $0.002)$. There was no significant difference in overall survival or disease-free survival in both the arms. This laryngeal preservation trial is somewhat unique in that it includes a mix of larynx and hypopharynx patients. It is somewhat problematic to compare this study with previous laryngeal preservation trials, as the patient inclusion and treatment criteria are different (hypopharynx patient inclusion and stipulation of functional larynx). The PF induction chemotherapy arm in the RTOG 91-11study showed better laryngeal preservation than the GORTEC trial ( $75 \%$ at 3.8 years vs. $58 \%$ at 3 years) because hypopharyngeal cancers were also included in the GORTEC trial.

TAX 324 and EORTC 24971/TAX 323 showed that TPF induction chemotherapy significantly improves survival compared with PF $[24,25]$. The subset analysis of patients with laryngohypopharyngeal cancer in TAX324 trial showed that TPF improves progression-free survival (PFS) and overall survival (OS), reduces the rates of locoregional surgery, and, in operable patients, results in a significant improvement in laryngectomy free survival (LFS) with an absolute improvement of $20 \%(52 \%$ vs. $32 \% ; \mathrm{P}=0.030)$ at 3 years compared with PF [26].

\section{Induction Chemotherapy Followed by CTRT}

Those trials decided the optimum induction chemotherapy regime but did not answer the important question regarding the relative efficacy of adding induction chemotherapy followed by CTRT compared with CTRT alone, the current standard of care. Newer studies such as DeCIDE [27] (Docetaxel-Based Chemotherapy Plus or Minus IC to Decrease Events in Head and Neck Cancer) and PARADIGM [28] suggest no overall benefit from the addition of induction chemotherapy vs. concomitant RT alone. Budach et al [29] in their meta-analysis showed that induction treatment with TPF followed by CTRT does not result in significant improvement in OS or PFS.

The comparison of landmark studies on laryngeal preservation in locally advanced laryngeal cancer is provided in 
Table 2 [19-21, 23].

\section{Biological Therapy in Organ Preservation}

Bonner et al [30] in their randomized trial of cetuximab with RT (CRT) vs. RT alone in head neck cancers (nearly $40 \%$ were laryngopharynx) demonstrated significant improvement in locoregional control (24.4 months vs. 14.9 months in cetuximab with RT and RT alone, respectively) as well as OS (49 months vs. 29.3 months) in those patients who received targeted therapy with RT. Although, these results were best seen in the subset of oropharyngeal cancers, there was a positive trend even in laryngopharynx. In a recent subgroup analysis of patients with hypopharyngeal and laryngeal cancers, Bonner et al analyzed the impact of cetuximab and RT in laryngeal preservation. The rates of laryngeal preservation were $87.9 \%$ at 2 and 3 years in the CRT group compared with $85.7 \%$ at 2 years and $76.8 \%$ at 3 years in the RT alone group. The $2.2 \%$ and $11.1 \%$ absolute improvements in the rates of laryngeal preservation at 2 and 3 years respectively favored CRT compared with RT alone but this improvement was not statistically significant (HR, 0.57; $95 \%$ CI, $0.23-1.42 ; \mathrm{P}=0.22$ ). In addition, there was a $4 \%$ and $8.9 \%$ absolute improvement in laryngectomy free survival at 2 and 3 years, respectively. However, this difference also could not reach statistical significance (HR, 0.78; 95\% CI, 0.54 $1.11 ; \mathrm{P}=0.17$ ) [31]. The targeted therapy plus radiotherapy approach has never been compared head on to concurrent CTRT, which still remains the standard of care.

\section{Consensus Panel Recommendation}

An international consensus panel was convened to develop guidelines for the conduct of phase III clinical trials of larynx preservation in patients with locally advanced laryngeal and hypopharyngeal cancer. According to their recommendations, future trial populations should include patients with T2 or T3 laryngeal or hypopharyngeal squamous cell carcinoma not considered for partial laryngectomy and should exclude those with laryngeal dysfunction or aged $>70$ years. Baseline and post-treatment functional assessments should include speech and swallowing evaluations. Furthermore, voice should be routinely assessed with a simple, validated instrument. Regarding endpoints, the primary endpoint should capture survival and function. As a result, the panel created a new endpoint of laryngesophageal dysfunction (LED)-free survival, which includes the events of death, local relapse, total or partial laryngectomy, tracheostomy at $>2$ years, or feeding tube at $>2$ years. Recommended secondary endpoints are freedom from LED, OS, PFS, locoregional control, time to tracheostomy, time to laryngectomy, time to discontinuation of feeding tube, and quality of life/patient-reported outcomes [32].

\section{Emerging Approach}

All patients with locally advanced head and neck cancer may not benefit from concurrent CTRT. The data regarding the reliable molecular markers predicting the response to CTRT is scarce. The excision repair cross-complementation group 1 (ERCC1) enzyme is a key element of the nucleotide excision repair pathway that removes cisplatin-induced DNA adducts and has been associated with resistance to platinum-based chemotherapy. Jun et al showed that in SCCHN patients, those with ERCC1negative tumors were more likely to derive a substantial benefit from cisplatin-based induction chemotherapy, translating to a lower risk for cancer-related death than in patients with ERCC1-positive tumors [33]. As a result, the evaluation of ERCC1 is recommended for future correlative biomarker studies.

\section{Conclusion}

The goal of treatment of laryngeal cancer is to achieve best oncologic outcome with optimum functional preservation. The treatment of early laryngeal cancer is radical RT or organ preserving surgery. However, RT is preferred because of excellent and equivalent tumor control, larynx preservation and better or equal voice quality and it is a time tested approach. For advanced laryngeal cancer, concurrent CTRT is the best organ preserving modality. Induction chemotherapy followed by RT/ CTRT has not shown benefit over upfront CTRT. Biological therapy is better as compared to RT alone in terms of laryngeal preservation; however, there is no head on comparison with CTRT. Emerging molecular markers are coming up which promise to individualize further treatment with optimum laryngeal preservation.

\section{References}

1. Ferlay J, Soerjomataram I, Ervik M, Forman D, Bray F, Dikshit R, et al. Lyon, France: International agency for research on cancer; 2012. [Last accessed on 2014 May 03]. GLOBOCAN 2012, Cancer Incidence and Mortality Worldwide in 2012. Available from: http://www.globocan.iarc.fr.

2. Three-year report of population based cancer registries 2009-2011. Bangalore: National Cancer Registry Program (ICMR); 2013. ICMR. Individual registry-wise annexure; pp. 92-150.

3. Mendenhall WM, Werning JW, Hinerman RW, Amdur RJ, Villaret DB. Management of T1-T2 glottic carcinomas. Cancer. 2004;100(9):1786-1792.

4. Abdurehim Y, Hua Z, Yasin Y, Xukurhan A, Imam I, Yuqin $F$. Transoral laser surgery versus radiotherapy: systematic review and meta-analysis for treatment options of T1a glottic cancer. Head Neck. 2012;34(1):23-33.

5. Aaltonen LM, Rautiainen N, Sellman J, Saarilahti K, Makitie A, Rihkanen H, Laranne J, et al. Voice quality after treatment of early vocal cord cancer: a randomized trial comparing laser surgery with radiation therapy. Int J Radiat Oncol Biol Phys. 2014;90(2):255-260.

6. Dinapoli N, Parrilla C, Galli J, Autorino R, Micciche F, Bussu F, Balducci M, et al. Multidisciplinary approach in the treatment of $\mathrm{T} 1$ glottic cancer. The role of patient 
preference in a homogenous patient population. Strahlenther Onkol. 2010;186(11):607-613.

7. Remmelts AJ, Hoebers FJ, Klop WM, Balm AJ, Hamming-Vrieze O, van den Brekel MW. Evaluation of lasersurgery and radiotherapy as treatment modalities in early stage laryngeal carcinoma: tumour outcome and quality of voice. Eur Arch Otorhinolaryngol. 2013;270(7):20792087.

8. Milovanovic J, Djukic V, Milovanovic A, Jotic A, Banko B, Jesic S, Babic B, et al. Clinical outcome of early glottic carcinoma in Serbia. Auris Nasus Larynx. 2013;40(4):394399.

9. van Gogh CD, Verdonck-de Leeuw IM, Wedler-Peeters J, Langendijk JA, Mahieu HF. Prospective evaluation of voice outcome during the first two years in male patients treated by radiotherapy or laser surgery for T1a glottic carcinoma. Eur Arch Otorhinolaryngol. 2012;269(6):16471652.

10. Ambrosch P, Fazel A. Functional organ preservation in laryngeal and hypopharyngeal cancer. GMS Curr Top Otorhinolaryngol Head Neck Surg. 2011;10:Doc02.

11. Thomas JV, Olsen KD, Neel HB, 3rd, DeSanto LW, Suman VJ. Early glottic carcinoma treated with open laryngeal procedures. Arch Otolaryngol Head Neck Surg. 1994;120(3):264-268.

12. Spector JG, Sessions DG, Chao KS, Hanson JM, Simpson JR, Perez CA. Management of stage II (T2N0M0) glottic carcinoma by radiotherapy and conservation surgery. Head Neck. 1999;21(2):116-123.

13. Warner L, Chudasama J, Kelly CG, Loughran S, McKenzie K, Wight R, Dey P. Radiotherapy versus open surgery versus endolaryngeal surgery (with or without laser) for early laryngeal squamous cell cancer. Cochrane Database Syst Rev. 2014;12:CD002027.

14. Mnejja M, Hammami B, Bougacha L, Chakroun A, Charfeddine I, Khabir A, Boudaoura T, et al. Occult lymph node metastasis in laryngeal squamous cell carcinoma: therapeutic and prognostic impact. Eur Ann Otorhinolaryngol Head Neck Dis. 2010;127(5):173-176.

15. Prades JM, Simon PG, Timoshenko AP, Dumollard JM, Schmitt T, Martin C. Extended and standard supraglottic laryngectomies: a review of 110 patients. Eur Arch Otorhinolaryngol. 2005;262(12):947-952.

16. Schwaab G, Kolb F, Julieron M, Janot F, Le Ridant AM, Mamelle G, Marandas P, et al. Subtotal laryngectomy with cricohyoidopexy as first treatment procedure for supraglottic carcinoma: Institut Gustave-Roussy experience (146 cases, 1974-1997). Eur Arch Otorhinolaryngol. 2001;258(5):246-249.

17. Laccourreye O, Brasnu D, Merite-Drancy A, Cauchois R, Chabardes E, Menard M, Laccourreye H. Cricohyoidopexy in selected infrahyoid epiglottic carcinomas presenting with pathological preepiglottic space invasion. Arch Otolaryngol Head Neck Surg. 1993;119(8):881886.

18. Chevalier D, Piquet JJ. Subtotal laryngectomy with cricohyoidopexy for supraglottic carcinoma: review of 61 cases. Am J Surg. 1994;168(5):472-473.

19. Department of Veterans Affairs Laryngeal Cancer Study
G, Wolf GT, Fisher SG, Hong WK, Hillman R, Spaulding $\mathrm{M}$, Laramore $\mathrm{GE}$, et al. Induction chemotherapy plus radiation compared with surgery plus radiation in patients with advanced laryngeal cancer. N Engl J Med. 1991;324(24):1685-1690.

20. Forastiere AA, Goepfert H, Maor M, Pajak TF, Weber R, Morrison W, Glisson B, et al. Concurrent chemotherapy and radiotherapy for organ preservation in advanced laryngeal cancer. N Engl J Med. 2003;349(22):2091-2098.

21. Forastiere AA, Zhang Q, Weber RS, Maor MH, Goepfert H, Pajak TF, Morrison W, et al. Long-term results of RTOG 91-11: a comparison of three nonsurgical treatment strategies to preserve the larynx in patients with locally advanced larynx cancer. J Clin Oncol. 2013;31(7):845852.

22. Weber RS, Berkey BA, Forastiere A, Cooper J, Maor M, Goepfert H, Morrison W, et al. Outcome of salvage total laryngectomy following organ preservation therapy: the Radiation Therapy Oncology Group trial 91-11. Arch Otolaryngol Head Neck Surg. 2003;129(1):44-49.

23. Pointreau Y, Garaud P, Chapet S, Sire C, Tuchais C, Tortochaux J, Faivre S, et al. Randomized trial of induction chemotherapy with cisplatin and 5-fluorouracil with or without docetaxel for larynx preservation. J Natl Cancer Inst. 2009;101(7):498-506.

24. Posner MR, Hershock DM, Blajman CR, Mickiewicz E, Winquist E, Gorbounova V, Tjulandin S, et al. Cisplatin and fluorouracil alone or with docetaxel in head and neck cancer. N Engl J Med. 2007;357(17):1705-1715.

25. Vermorken JB, Remenar E, van Herpen C, Gorlia T, Mesia R, Degardin M, Stewart JS, et al. Cisplatin, fluorouracil, and docetaxel in unresectable head and neck cancer. N Engl J Med. 2007;357(17):1695-1704.

26. Lorch JH, Goloubeva O, Haddad RI, Cullen K, Sarlis $\mathrm{N}$, Tishler $\mathrm{R}$, Tan $\mathrm{M}$, et al. Induction chemotherapy with cisplatin and fluorouracil alone or in combination with docetaxel in locally advanced squamous-cell cancer of the head and neck: long-term results of the TAX 324 randomised phase 3 trial. Lancet Oncol. 2011;12(2):153159.

27. Cohen EE, Karrison TG, Kocherginsky M, Mueller J, Egan R, Huang CH, Brockstein BE, et al. Phase III randomized trial of induction chemotherapy in patients with N2 or N3 locally advanced head and neck cancer. J Clin Oncol. 2014;32(25):2735-2743.

28. Haddad R, O'Neill A, Rabinowits G, Tishler R, Khuri F, Adkins D, Clark J, et al. Induction chemotherapy followed by concurrent chemoradiotherapy (sequential chemoradiotherapy) versus concurrent chemoradiotherapy alone in locally advanced head and neck cancer (PARADIGM): a randomised phase 3 trial. Lancet Oncol. 2013;14(3):257264.

29. Budach W, Bolke E, Kammers K, Gerber PA, Orth K, Gripp S, Matuschek C. Induction chemotherapy followed by concurrent radio-chemotherapy versus concurrent radio-chemotherapy alone as treatment of locally advanced squamous cell carcinoma of the head and neck (HNSCC): A meta-analysis of randomized trials. Radiother Oncol. 2016;118(2):238-243. 
30. Bonner JA, Harari PM, Giralt J, Azarnia N, Shin DM, Cohen RB, Jones CU, et al. Radiotherapy plus cetuximab for squamous-cell carcinoma of the head and neck. N Engl J Med. 2006;354(6):567-578.

31. Bonner J, Giralt J, Harari P, Spencer S, Schulten J, Hossain A, Chang SC, et al. Cetuximab and radiotherapy in laryngeal preservation for cancers of the larynx and hypopharynx: a secondary analysis of a randomized clinical trial. JAMA Otolaryngol Head Neck Surg. 2016;142(9):842-
849.

32. Ang KK. Larynx preservation clinical trial design: summary of key recommendations of a consensus panel. Oncologist. 2010;15(Suppl 3):25-29.

33. Jun HJ, Ahn MJ, Kim HS, Yi SY, Han J, Lee SK, Ahn YC, et al. ERCC1 expression as a predictive marker of squamous cell carcinoma of the head and neck treated with cisplatin-based concurrent chemoradiation. Br J Cancer. 2008;99(1):167-172. 